\title{
Drug-eluting scaffold to deliver chemotherapeutic medication for management of pancreatic cancer after surgery
}

This article was published in the following Dove Press journal:

International Journal of Nanomedicine

10 July 2013

Number of times this article has been viewed

\author{
Qian Zhan' \\ Baiyong Shen' \\ Xiaxing Deng' \\ Hao Chen' \\ Jiabin Jin' \\ Xing Zhang ${ }^{2}$ \\ Chenghong Peng' \\ Hongwei Li' \\ 'Department of General Surgery, \\ Rui Jin Hospital, School of Medicine, \\ Shanghai Jiao Tong University, \\ Shanghai, People's Republic of China; \\ ${ }^{2}$ Department of Surgery, University \\ of Chicago, Chicago, IL, USA
}

\begin{abstract}
Traditional post-surgical chemotherapy for pancreatic cancer is notorious for its devastating side effects due to the high dosage required. On the other hand, legitimate concerns have been raised about nanoparticle-mediated drug delivery because of its potential cytotoxicity. Therefore, we explored the local delivery of a reduced dosage of FOLFIRINOX, a four-drug regimen comprising oxaliplatin, leucovorin, irinotecan, and fluorouracil, for pancreatic cancer using a biocompatible drug-eluting scaffold as a novel chemotherapy strategy after palliative surgery. In vitro assays showed that FOLFIRINOX in the scaffold caused massive apoptosis and thereby a decrease in the viability of pancreatic cancer cells, confirming the chemotherapeutic capability of the drug-eluting scaffold. In vivo studies in an orthotopic murine xenograft model demonstrated that the FOLFIRINOX in the scaffold had antitumorigenic and antimetastatic effects comparable with those achieved by intraperitoneal injection, despite the dose released by the scaffold being roughly two thirds lower. A mechanistic study attributed our results to the excellent ability of the FOLFIRINOX in the scaffold to destroy the $\mathrm{CD} 133^{+} \mathrm{CXCR} 4^{+}$cell population responsible for pancreatic tumorigenesis and metastasis. This clinically oriented study gives rise to a promising alternative strategy for postsurgical management of pancreatic cancer, featuring a local chemotherapeutic effect with considerable attenuation of side effects.
\end{abstract}

Keywords: electrospun scaffold, FOLFIRINOX, pancreatic cancer, drug-eluting scaffold

\section{Introduction}

Pancreatic cancer remains a great risk for patients because it develops without manifesting definite symptoms until it reaches a late stage, resulting in a $4 \%$ survival rate 5 years after diagnosis. ${ }^{1}$ Cancer genetics research indicates that a large panel of inherited genes is involved in pancreatic cancer and suggests that this disease might have a global root and undergo systemic evolution without manifesting itself. ${ }^{2}$ The most common treatment plan is removal of the tumor tissue via potentially curative or palliative surgery, which is usually followed by postoperative chemotherapy to pre-empt recurrence. Postsurgical chemotherapy, be it systemic or regional, requires a high anticancer drug dosage to achieve the desired effect due to the significant loss of drugs before they reach their target cancer cells, thus giving rise to a wide range of devastating side effects, including anemia and diarrhea.

These limitations prompted scientists to develop novel tools to enhance drug delivery targeting cancer cells, with the expectation that improved targeting would reduce the dose required and side effects. To that end, the last two decades have seen a burgeoning of research on nanoparticles as delivery vehicles for various drugs and/or biological molecules to combat cancer. ${ }^{3-6}$ For example, Doxil ${ }^{\circledR}$ (Johnson \& Johnson, New Brunswick, NJ, USA)
Correspondence: Baiyong Shen Department of General Surgery, Rui Jin Hospital, Shanghai Jiao Tong University, 197 Ruijin 2nd Road, Shanghai 200025, People's Republic of China

Fax +862154660106

Email shenbaiyong@hotmail.com 
is a polyethylene glycosylated liposome that has been engineered to carry doxorubicin, an anticancer drug, and is approved for the treatment of breast cancer. ${ }^{7}$ However, the nanoparticles themselves often pose a cytotoxic threat to patients because of their chemistry and/or interaction with cells and organs, raising legitimate concerns about their application in the treatment of cancer. $^{8-11}$ For example, Doxil has been reported to have many side effects in humans, including low blood counts, dermatitis, and leukopenia. ${ }^{12-15}$ Cationic liposomes can cause liver damage and pulmonary inflammation by induction of reactive oxygen species. ${ }^{16-18}$ Dextran, a glucose polymer used for drug delivery, is reported to cause anaphylaxis, pulmonary edema, and even acute renal failure. ${ }^{19,20}$ Further, nanoparticles made of metal, in particular gold and silver, have been found to be the culprits in cell death induced by free radicals, destruction of the blood-brain barrier, and depletion of glutathione, amongst other side effects. ${ }^{21-23}$

In addition to nanoparticles, tissue-engineered scaffolds are often functionalized to carry a payload of cytokines that trigger local tissue regeneration. ${ }^{24-26}$ The materials used to build tissue-engineered scaffolds are usually biocompatible synthetic polymers and/or natural proteins, both of which possess no or minimal cytotoxicity. ${ }^{27-29}$ The fact that tissueengineered scaffolds can carry payloads, degrade in vivo, and are removed by metabolism make them appealing candidates as drug delivery vehicles. ${ }^{30,31}$ Based on our clinical experience, we conceptualized that a drug-eluting scaffold can be grafted to cancer tissue remaining after palliative surgery for local delivery of FOLFIRINOX, a pancreatic chemotherapeutic regimen comprising oxaliplatin, leucovorin, irinotecan, and fluorouracil, to arrest tumorigenesis and metastasis. Based on our previous research, in this study we fabricated an electrospun scaffold composed of polyglycolide-co-trimethylene carbonate (PGA-TMC) and gelatin loaded with FOLFIRINOX, and evaluated its ability to arrest pancreatic tumorigenesis and metastasis in an orthotopic murine xenograft model. ${ }^{32}$ We aimed to determine whether a low dosage of FOLFIRINOX delivered locally by a scaffold could have antitumorigenic and antimetastatic effects comparable with those achieved by the higher dosages used in traditional regional chemotherapy.

\section{Materials and methods}

\section{Construction and characterization of electrospun scaffolds}

PGA-TMC (Advanced Inventory Management, Mokena, IL, USA) and porcine gelatin A (Sigma-Aldrich, St Louis, MO, USA) were used as received. FOLFIRINOX was obtained from Rui Jin Hospital. A blended solution was prepared by dissolving PGA-TMC and gelatin in 1,1,1,3,3,3-hexafluoro2-propanol (Sigma-Aldrich) at a $12 \%(\mathrm{w} / \mathrm{v})$ concentration (weight ratio 5:1). For the drug-eluting scaffolds, oxaliplatin $80 \mu \mathrm{g} / \mathrm{mL}$, leucovorin $300 \mu \mathrm{g} / \mathrm{mL}$, irinotecan $140 \mu \mathrm{g} / \mathrm{mL}$, and fluorouracil $2.1 \mathrm{mg} / \mathrm{mL}$ were added to the blended solution. The solution loaded into a motorized pump syringe at a feeding rate of $3 \mathrm{~mL}$ per hour was electrospun to a collector distanced at $25 \mathrm{~cm}$ with a voltage of $30 \mathrm{kV}$. A total of $0.5 \mathrm{~mL}$ of solution was electrospun at a time. For the non-eluting scaffolds, the blended solution without FOLFIRINOX was electrospun under the same conditions. After electrospinning, the scaffolds were desiccated in a vacuum for 24 hours. The morphology of the electrospun fibers in the scaffold was characterized by scanning electron microscopy. A total of 100 fibers in each image was randomly selected for measurement of fiber diameter by ImageJ software. Drug-eluting scaffolds $(1 \mathrm{~cm} \times 1 \mathrm{~cm})$ were incubated in $2 \mathrm{~mL}$ aliquots of cell medium at $37^{\circ} \mathrm{C}$ and $5 \% \mathrm{CO}_{2}$ for up to 3 weeks. A high-performance liquid chromatography system equipped with a Symmetry $\mathrm{C}_{18}$ column (Waters Corporation, Milford, MA, USA) was calibrated to measure the in vitro kinetics of drug release in the aliquots of medium.

\section{Harvesting of pancreatic cancer cells and $\mathrm{CDI} 33^{+} \mathrm{CXCR} 4^{+}$cells}

The pancreatic cancer tissues used in this study were resected from human patients at Rui Jin Hospital. Written consent was obtained from the patients prior to resection. Cancer tissues were minced completely using sterile scissors and blades. The minced cancer tissues were disassociated into individual cell suspensions using a method reported previously. ${ }^{32}$ $\mathrm{CD} 133{ }^{+} \mathrm{CXCR} 4^{+}$cells were sorted by fluorescence-activated cell sorting (BD LSRII, BD Biosciences, San Jose, CA, USA) using antihuman CD133 (Miltenyi Biotec, Auburn, CA, USA) and antihuman CXCR4 (R\&D systems, Minneapolis, MN, USA) antibodies.

\section{Analyses of in vitro viability and apoptosis of pancreatic cancer cells}

Both drug-eluting and non-eluting scaffolds (diameter $6 \mathrm{~mm}$ ) were prepared as described above and sterilized in $70 \%$ ethanol. Pancreatic cancer cells were cultured on the scaffold $\left(36\right.$ cells $/ \mathrm{mm}^{2}$ ) at $37^{\circ} \mathrm{C}$ and $5 \% \mathrm{CO}_{2}$ for up to 3 weeks. Viability and apoptosis in the cell populations were measured using a 3-(4,5-dimethylthiazol-2-yl)-2,5-diphenyltetrazolium bromide (MTT) assay kit and a Caspase-Glo ${ }^{\circledR}$ 3/7 assay kit, respectively, as per the manufacturer's protocols (Promega, Madison, WI, USA). Pancreatic cancer cells cultured 
in a $96-w e l l$ tissue culture plate $\left(36\right.$ cells $\left./ \mathrm{mm}^{2}\right)$ was used as the control.

\section{Analyses of in vivo tumorigenesis and metastasis in pancreatic cancer cells}

Resected pancreatic cancer tissues were cut into small pieces about $4 \mathrm{~mm} \times 4 \mathrm{~mm}$ in area. One piece was grafted to a drug-eluting or non-eluting scaffold prepared from $0.25 \mathrm{~mL}$ of the respective solutions, as described above. An orthotopic murine xenograft model was constructed following an established protocol. ${ }^{33}$ Briefly, female BALB/c nu/ nu mice (aged 4-6 weeks, Shanghai Laboratory Animal Co, Shanghai, People's Republic of China) were anesthetized using vaporized isoflurane and maintained in the supine position. The abdomen was opened with surgical scissors and the pancreas was exposed. The mice were randomly divided into three groups: a drug-eluting scaffold group that would receive a piece of cancer tissue on a drug-eluting scaffold; a non-eluting scaffold/FOLFIRINOX group that would receive a piece of cancer tissue on a non-eluting scaffold followed by intraperitoneal injection of FOLFIRINOX; a non-eluting scaffold/phosphate-buffered solution group that would receive a piece of cancer tissue on a non-eluting scaffold followed by intraperitoneal injection of phosphatebuffered solution. In the non-eluting scaffold/FOLFIRINOX group, FOLFIRINOX was administered by intraperitoneal injection every week for a total of 3 weeks. Specifically, at every administration of the trial preparation, each mouse first received oxaliplatin $4 \mathrm{mg} / \mathrm{kg}$ and leucovorin $20 \mathrm{mg} / \mathrm{kg}$, and 30 minutes later received irinotecan $9 \mathrm{mg} / \mathrm{kg}$ and fluorouracil $140 \mathrm{mg} / \mathrm{kg}$. The dosage of FOLFIRINOX was determined based on previous research. ${ }^{34}$ Mice used as controls received the same amount of non-eluting scaffold/phosphate-buffered solution following the same schedule. All mice were euthanized 3 weeks after surgery. The animal study was approved by Rui Jin Hospital. Following euthanasia, the cancer tissues were retrieved for measurement of tumor volume and weight. Cancer tissue volume was calculated using a previously reported method. ${ }^{32}$ Liver tissues were harvested and processed into single cell suspensions as described above. Cells expressing carbohydrate antigen 19-9 (CA199) were probed by flow cytometry using antihuman CA199 antibody (Abcam, Cambridge, MA, USA).

\section{Anticancer effects on $\mathrm{CDI} 33^{+} \mathrm{CXCR} 4^{+}$ cells}

$\mathrm{CD} 133^{+} \mathrm{CXCR}^{+}$cells $\left(180\right.$ cells $/ \mathrm{mm}^{2}$ ) were incubated on sterilized scaffolds (diameter $6 \mathrm{~mm}$ ) at $37^{\circ} \mathrm{C}$ and $5 \% \mathrm{CO}_{2}$ for
48 hours. Samples were randomly divided into three groups: a drug-eluting scaffold group in which standard cell medium was used; a non-eluting scaffold/FOLFIRINOX group in which the cell medium was supplemented with oxaliplatin $8 \mathrm{nM}$, leucovorin $40 \mathrm{nM}$, irinotecan $20 \mathrm{nM}$, and fluorouracil $280 \mathrm{nM}$; and a non-eluting scaffold/phosphate-buffered solution group in which the cell medium was supplemented with phosphate-buffered solution as a control. The degree of apoptosis of $\mathrm{CD} 133^{+} \mathrm{CXCR} 4^{+}$cells was measured using a Caspase-Glo 3/7 assay kit at 4 and 48 hours, respectively.

\section{Data analysis}

All images were analyzed using ImageJ software. Flow cytometric data were analyzed and presented using FlowJo (Tree Star Inc, Ashland, OR, USA). One-way analysis of variance with Tukey's test was used to identify statistically significant differences $(\alpha=0.05)$.

\section{Results and discussion Physical characterizations of fibers in electrospun scaffolds}

Both the non-eluting and drug-eluting scaffolds demonstrated a highly porous microstructure composed of randomly distributed fibers in the microsized range (Figure 1). In addition, no marked difference in fiber morphology was observed between the two types of scaffolds, suggesting that incorporation of FOLFIRINOX did not introduce any structural changes. The lack of a discrepancy in fiber morphology ruled out the possibility that differences between subsequent biological readouts were

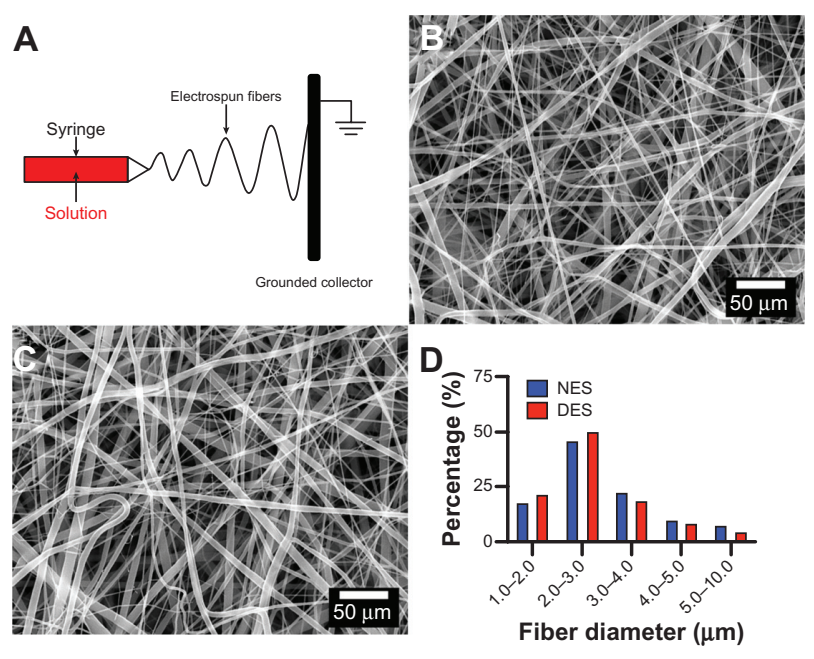

Figure I Morphologic characterization of scaffolds. (A) Schematic illustration of electrospinning, (B) non-eluting scaffolds, (C) drug-eluting scaffolds, and (D) distribution of fiber diameter. No marked difference in fiber morphology was observed, suggesting that incorporation of FOLFIRINOX did not introduce structural changes into the scaffolds.

Abbreviations: NES, non-eluting scaffolds; DES, drug-eluting scaffolds. 
due to structural changes in the scaffolds. The in vitro pharmacokinetic study showed that all four drugs in the FOLFIRINOX regimen were released rapidly in the first week followed by a steady increase through week 3 (Figure 2). The accumulative amount barely increased beyond week 3 for all four drugs. The rapid release in the first week could be attributed to the fast disintegration of gelatin in the scaffold, as reported by previous researchers. ${ }^{35,36}$ Drug delivery vehicles made of biodegradable polymers have been extensively investigated. For example, hydrogels have been shown to be able to deliver a variety of payloads. ${ }^{37,38}$ It should be noted that drug release mechanisms vary between these vehicles. The release of FOLFIRINOX from our scaffold could be attributed to the combined effect of physical disintegration and chemical decomposition. ${ }^{36}$ The high dose resulting from this rapid release would be advantageous in the management of pancreatic cancer because it would quickly and effectively destroy any cancer cells remaining after palliative surgery. Release of the incorporated FOLFIRINOX suggests that the scaffold could be used as a convenient vehicle for delivery of chemotherapeutic drugs in the postsurgical management of cancer. Most patients with pancreatic cancer survive only a few months after surgery and bear cancer tissue until the point of death. Therefore, under most circumstances, the goal of surgery and/or chemotherapy is to delay rather than eliminate tumorigenesis and metastasis. Considering these limitations, sustained release of FOLFIRINOX from the scaffold during the 3 weeks following surgery has clinical significance. Previous research on composite polymer/gelatin scaffolds shows that the entire degradation process can take up
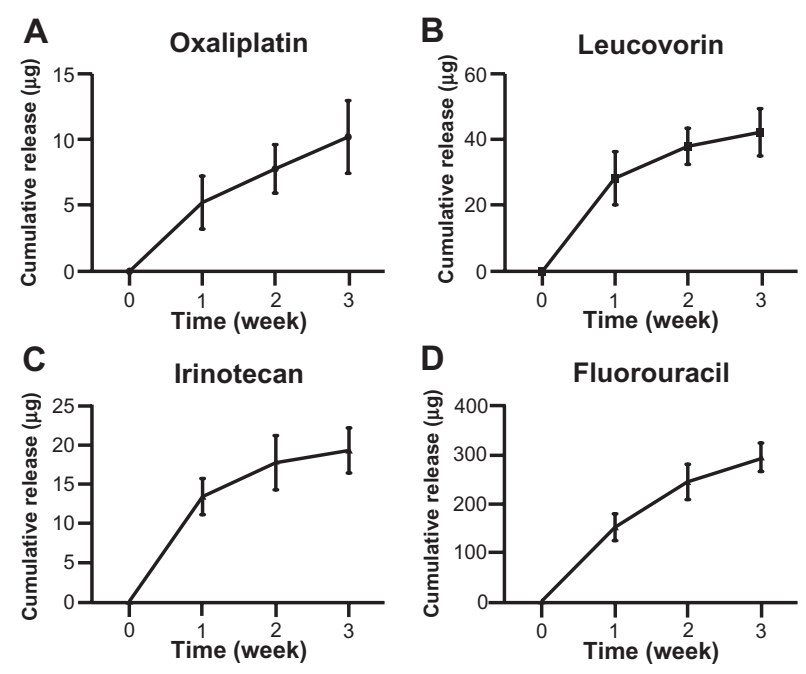

Figure 2 Pharmacokinetics of FOLFIRINOX regimen. (A) Oxaliplatin, (B) leucovorin, (C) irinotecan, and (D) fluorouracil. All four drugs showed a rapid release in the first week, probably due to rapid disintegration of gelatin in the scaffold.

Notes: No significant increase in accumulative release was observed after 3 weeks. $\mathrm{n}=3$ in all groups. to 8 weeks in vitro, with no cytotoxic effects found in vivo. ${ }^{32,35}$ From clinical experience, we know that pancreatic cancer has often metastasized to a number of organs by the time of diagnosis and surgery, so a drug delivery vehicle needs to have a high degree of dimensional and pharmacokinetic versatility. ${ }^{38}$ Electrospinning technology can easily fabricate scaffolds of various dimensions to accommodate clinical needs and provide complex microarchitecture (eg, multilayers) to achieve sophisticated pharmacokinetics with an extended-release window. ${ }^{35,40-44}$

\section{In vitro anticancer effect of drug-eluting scaffolds}

The MTT assay showed that only proliferation of pancreatic cancer cells on the drug-eluting scaffolds was arrested during the 3-week period of observation (Figure 3). The pancreatic cancer cell population on the drug-eluting scaffolds showed moderate proliferation in the first week followed by virtual arrest through week 3 . In contrast, pancreatic cancer cell populations on the non-eluting scaffolds and tissue culture plates increased dramatically through week 3 . The viability of cell populations on the drug-eluting scaffolds was different from those on the non-eluting scaffolds and tissue culture plates at weeks 2 and 3 . The apoptosis assay showed that apoptosis of the pancreatic cancer cell populations on the drug-eluting scaffolds escalated through week 3 (Figure 4). However, no significant apoptosis was observed in cancer cell populations on either the non-eluting scaffolds or the tissue culture plates during the 3-week study period.

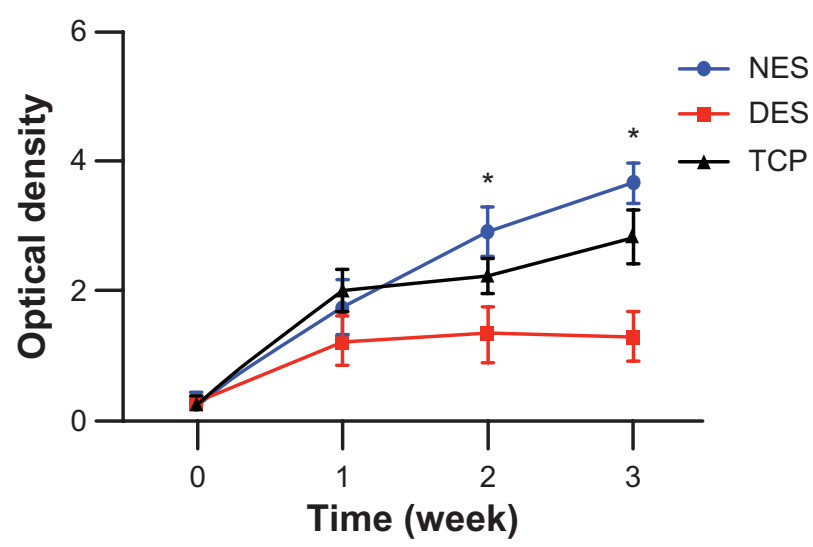

Figure 3 Viability of pancreatic cancer cells. Viability had no change in the drugeluting scaffold group because of release of FOLFIRINOX. Without FOLFIRINOX, pancreatic cancer cells grew rapidly in the non-eluting scaffold and tissue culture plate groups. Growth of pancreatic cancer cells on non-eluting scaffolds confirmed lack of cytotoxicity of the scaffolding materials.

Notes: $\mathrm{n}=3$ in all groups. *Significant difference between groups by analysis of variance followed by Tukey's test.

Abbreviations: DES, drug-eluting scaffold; NES, non-eluting scaffold; TCP, tissue culture plate. 


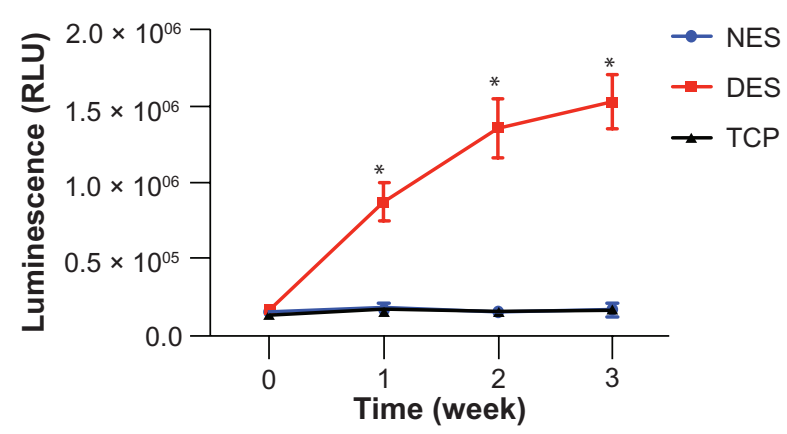

Figure 4 Apoptosis of pancreatic cancer cells. FOLFIRINOX from drug-eluting scaffolds caused the most apoptosis through week 3 in pancreatic cancer cells whereas no apoptosis was observed in populations in either the non-eluting scaffold or tissue culture plate groups.

Notes: $\mathrm{n}=3$ in all groups. *Significant difference between groups by analysis of variance followed by Tukey's test.

Abbreviations: DES, drug-eluting scaffold; NES, non-eluting scaffold; TCP, tissue culture plate; RLU, relative luminescent unit.

PGA-TMC is a synthetic polymer used widely in degradable surgical sutures, with no known cytotoxicity either in vitro or in vivo. Previous research confirms that PGA-TMC and gelatin can be used safely as scaffolding materials for tissue engineering purposes..$^{32,35}$ Recent clinical trials showed that FOLFIRINOX was a potent chemotherapeutic regimen for pancreatic cancer despite its side effect profile.$^{34}$ Consequently, it can be concluded that the arrested proliferation and significant apoptosis of pancreatic cancer cells on drug-eluting scaffolds could be attributed to the FOLFIRINOX released. These in vitro results confirm that drug-eluting scaffolds can prevent tumorigenesis by inducing dramatic apoptosis in pancreatic cancer cells, and are therefore a promising tool in the management of pancreatic cancer after palliative surgery.

\section{In vivo antitumorigenic and antimetastatic effect of drug-eluting scaffolds}

To mimic pancreatic cancer after palliative surgery, we exploited a proven orthotopic murine model of metastatic pancreatic cancer. ${ }^{33}$ The respective scaffolds were grafted to resected human pancreatic cancer tissues and surgically placed in the pancreas of each mouse. The antitumorigenic and antimetastatic effects of the drug-eluting scaffolds were confirmed in vivo. By the end of 3 weeks of in vivo tumorigenesis, the mean pancreatic tumor volume was $302.24 \pm 103.59 \mathrm{~mm}^{3}$ in the drug-eluting scaffold group, $434.22 \pm 132.98 \mathrm{~mm}^{2}$ in the non-eluting scaffold/ FOLFIRINOX group, and $951.78 \pm 178.21 \mathrm{~mm}^{2}$ in the noneluting scaffold/phosphate-buffered solution group, respectively (Figure 5A). Correspondingly, the mean tumor weight was $47.59 \pm 28.19 \mathrm{mg}$ in the drug-eluting scaffold group,
$53.23 \pm 19.27 \mathrm{mg}$ in the non-eluting scaffold/FOLFIRINOX group, and $132.04 \pm 35.33 \mathrm{mg}$ in the non-eluting scaffold/ phosphate-buffered solution group, respectively (Figure 5B). FOLFIRINOX, either released from a drug-eluting scaffold or administered via intraperitoneal injection successfully stabilized tumor volume and weight. Hepatic metastasis of pancreatic cancer cells was prevented in mice from the drugeluting scaffold group but still occurred to a minor degree in mice from the non-eluting scaffold/FOLFIRINOX group (Figure 6). In contrast, significant hepatic metastasis was observed in mice from the non-eluting scaffold group.

Recent clinical trials have shown that FOLFIRINOX is the most promising chemotherapeutic regimen discovered in the last two decades for advanced metastatic pancreatic cancer. ${ }^{34}$ The median overall survival was 11.1 months in FOLFIRINOX-treated patients as compared with 6.6 months in patients treated with gemcitabine, which is currently first-line chemotherapy in clinical practice. Unfortunately, the enhanced chemotherapeutic capacity of FOLFIRINOX is associated with increased toxicity, so this regimen is not suitable for all patients with pancreatic cancer. For example, $5.4 \%$ of patients were reported to suffer febrile neutropenia, and diminished quality of life due to FOLFIRINOX was observed in $31 \%$ of patients. It is largely these grave side effects that have prevented FOLFIRINOX from becoming established as standard chemotherapy for pancreatic cancer. This has prompted scientists to explore methods for diminishing the toxic effects of FOLFIRINOX without compromising its chemotherapeutic capability. We agree that a reduced dosage as well as targeted delivery of anticancer drugs to cancer cells would be the avenue ultimately leading to success. In addition to nanoparticles, electrospun scaffolds have attracted considerable attention in recent years for their ability to deliver drugs in situ. ${ }^{30,31}$ We consider that electrospun scaffolds have some critical advantages for local anticancer drug delivery after palliative surgery. First of all, scaffolding materials are usually synthetic polymers and/ or natural proteins with excellent in vivo biocompatibility, greatly defusing concerns about the cytotoxicity associated with the chemistry of delivery vehicles. Further, these biocompatible scaffolding materials degrade readily in vivo and can be removed via metabolism instead of accumulating in the body and being toxic to certain organs. Finally, electrospinning technology is highly versatile and reliable, and offers customized solutions to challenging problems in many circumstances. Complex electrospun scaffold microstructures (eg, multilayered, coaxial) can be easily fabricated to allow fine-tuning of pharmacokinetics. ${ }^{35,45}$ 
A

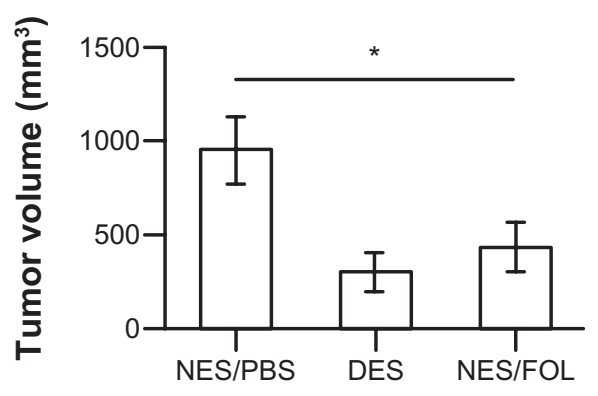

B

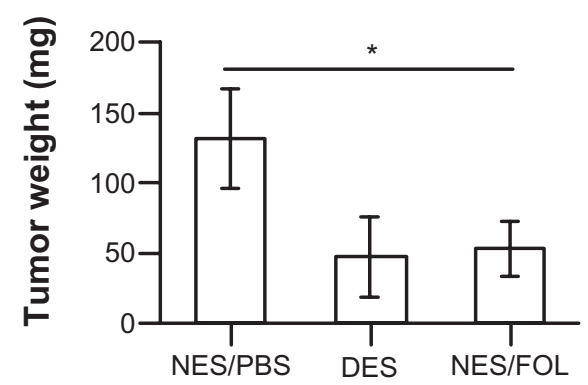

Figure $\mathbf{5}$ In vivo tumor growth in an orthotopic murine model. (A) Tumor volume and (B) tumor weight. FOLFIRINOX from the DES scaffolds showed an ability to prevent tumorigenesis similar to that of intraperitoneal injection despite a much reduced dosage. Scaffolding materials alone (NES) demonstrated no capability to inhibit tumor growth.

Notes: $n=5$ in the NES/PBS group; $n=7$ in the DES group; $n=5$ in the NES/FOL group. *Significant difference between groups by analysis of variance followed by Tukey's test. Abbreviations: DES, drug-eluting scaffold; NES, non-eluting scaffold; PBS, phosphate-buffered solution; FOL, FOLFIRINOX.

Our results highlight the fact that drug-eluting scaffolds can successfully arrest tumorigenesis and hepatic metastasis, a hallmark of pancreatic cancer, due to their ability to release FOLFIRINOX. Previous research has shown that scaffolding materials alone would not restrict tumorigenesis or metastasis. ${ }^{33}$ Our drug-eluting scaffolds demonstrated a level of antitumorigenic and antimetastatic ability comparable with that of traditional regional FOLFIRINOX chemotherapy (given by intraperitoneal injection) despite the dosage of FOLFIRINOX released from drug-eluting scaffolds being just a fraction of that delivered by intraperitoneal injection. It is well known that only a fraction of the dose of an anticancer drug injected intraperitoneally ultimately reaches the target cancer cells. ${ }^{3,10}$ In contrast, local delivery via a drug-eluting scaffold allows most of the FOLFIRINOX to have an effect on cancer cells. Our results show that local delivery of FOLFIRINOX using a drug-eluting scaffold would require a reduced dose, which might translate into attenuation of side effects, without compromising the overall effectiveness of postsurgical chemotherapy.

\section{Anticancer mechanism of drug-eluting scaffolds}

Recent cancer research suggests that a small population of cells in cancer tissue, termed cancer stem cells, are implicated in tumorigenesis and metastasis. ${ }^{46}$ It has been discovered that cancer stem cells are not born equal and that different subtypes of cancer stem cells have different functions, including promoting tumorigenesis and metastasis. ${ }^{47}$ Further, the number of surface markers associated with cancer stem cells varies from one type of cancer to another, and continues to grow with progress in cancer research. In particular, $\mathrm{CD} 133^{+} \mathrm{CXCR} 4{ }^{+}$cells are believed to be the driving force for tumorigenesis and metastasis in pancreatic cancer. ${ }^{48,49}$ Based
DES

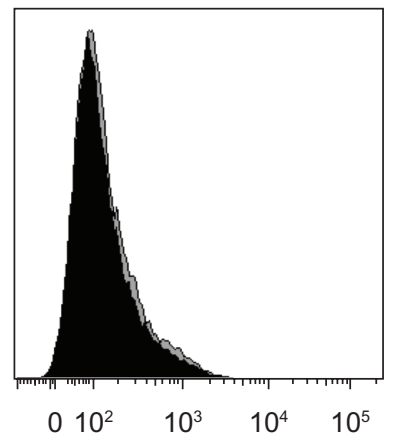

NES/FOL

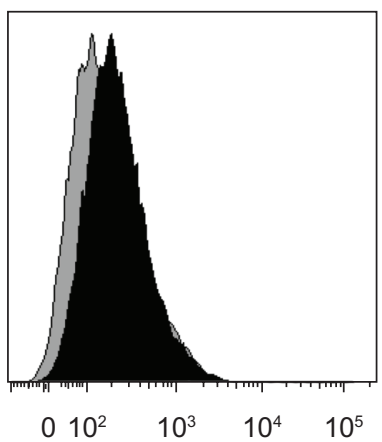

NES/PBS

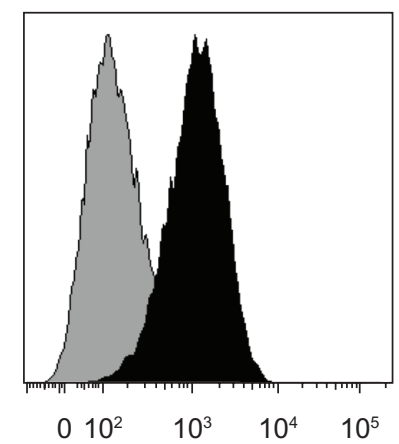

Figure 6 Representative flow cytometric histograms for hepatic metastasis of CA199+ pancreatic cancer cells. Hepatic metastasis of CAI99+ cells was almost completely prevented in the DES group but occurred to a very minor degree in the NES/FOL group, suggesting that DES scaffolds had an antimetastatic capability comparable with that of intraperitoneally injected FOLFIRINOX. Black: samples; Gray: isotype controls. The shifting degree of the black histogram from the gray one corresponds to the size of the $\mathrm{CA} 199^{+}$population in hepatic tissue.

Abbreviations: DES, drug-eluting scaffold; NES, non-eluting scaffold; PBS, phosphate-buffered solution; FOL, FOLFIRINOX. 


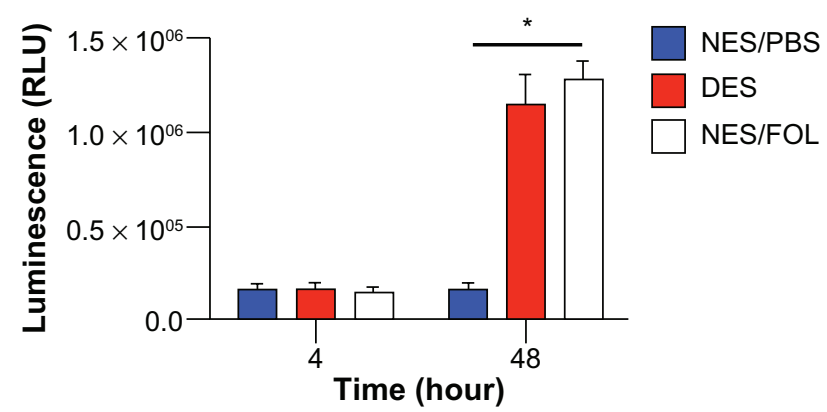

Figure 7 Apoptosis of $\mathrm{CDI} 33^{+} \mathrm{CXCR} 4^{+}$cells. At 48 hours, FOLFIRINOX released from DES scaffolds caused a comparable apoptosis to that observed in the NES group, which received FOLFIRINOX from the cell media. This result might account for the antitumorigenic and antimetastatic capabilities of DES scaffolds.

Notes: $\mathrm{n}=3$ in all groups. *Significant difference between groups by analysis of variance followed by Tukey's test.

Abbreviations: DES, drug-eluting scaffold; NES, non-eluting scaffold; PBS phosphate-buffered solution; FOL, FOLFIRINOX; RLU, relative luminescent unit.

on previous research, we hypothesized that the anticancer capability of drug-eluting scaffolds could be attributed to their chemotherapeutic effect on $\mathrm{CD} 133^{+} \mathrm{CXCR} 4^{+}$cells To test this hypothesis, we cultured $\mathrm{CD} 133^{+} \mathrm{CXCR} 4^{+}$cells on respective scaffolds and measured levels of apoptosis thereafter. No significant difference was observed between the groups at 4 hours; however, differences in the rate of apoptosis between the drug-eluting and non-eluting scaffold/FOLFIRINOX groups emerged at 48 hours (Figure 7). No difference was observed between the drug-eluting and non-eluting scaffold/FOLFIRINOX groups, suggesting that incorporation of FOLFIRINOX into the scaffold did not reduce its anticancer efficacy. This result suggests that FOLFIRINOX-induced apoptosis of $\mathrm{CD} 133^{+} \mathrm{CXCR} 4^{+}$cells might contribute greatly to the anticancer capability of drugeluting scaffolds. We measured apoptosis during a 48-hour window because cancer stem cells differentiate rapidly into various cancer cells upon adhering to a substrate.

\section{Conclusion}

FOLFIRINOX, the most promising chemotherapeutic regimen for pancreatic cancer, extends the mean survival time to 11 months, but has grave side effects. To minimize these side effects while preserving chemotherapeutic efficacy, we believe that localized delivery of a reduced dose would be the most cost-effective treatment strategy. Therefore, we explored local delivery of FOLFIRINOX to pancreatic cancer tissue using a drug-eluting scaffold in an orthotopic murine model. Compared with traditional systemic or regional chemotherapy, local drug delivery by a drug-eluting scaffold reduced the dosage required to achieve a comparable anticancer effect by roughly two thirds. FOLFIRINOX from drug-eluting scaffolds successfully stabilized tumorigenesis and prevented hepatic metastasis because of its ability to destroy $\mathrm{CD} 133{ }^{+} \mathrm{CXCR} 4^{+}$cells in cancer tissue.

We recognize some limitations to this approach. For example, we could not control the distribution of loaded drug molecules in the fibers in a convenient manner, which might potentially give rise to heterogeneous distribution of chemotherapeutic agents. Also, the shelf-life of the drugeluting scaffold may not be long, even though we have not yet carried out a systematic storage study. Our work sheds new light on the development of novel strategies to manage residual pancreatic cancer tissue after palliative surgery. Also, the versatility of electrospinning technology will allow this prototype to evolve into more sophisticated schemes, for example, multidrug delivery to combat various types of cancers.

\section{Acknowledgment}

The authors acknowledge the financial support of the Chinese Ministry of Health Sector Funds (grant 201002020).

\section{Disclosure}

The authors declare no conflict of interest in this work.

\section{References}

1. Vincent A, Herman J, Schulick R, Hruban RH, Goggins M. Pancreatic cancer. Lancet. 2011;378(9791):607-620.

2. Li D, Xie K, Wolff R, Abbruzzese JL. Pancreatic cancer. Lancet. 2004;363(9414):1049-1057.

3. Wang AZ, Langer R, Farokhzad OC. Nanoparticle delivery of cancer drugs. Annu Rev Med. 2012;63:185-198.

4. Irvine DJ. Drug delivery: one nanoparticle, one kill. Nat Mater. 2011;10(5):342-343.

5. Davis ME, Chen ZG, Shin DM. Nanoparticle therapeutics: an emerging treatment modality for cancer. Nat Rev Drug Discov. 2008; 7(9):771-782.

6. Brannon-Peppas L, Blanchette JO. Nanoparticle and targeted systems for cancer therapy. Adv Drug Deliv Rev. 2004;56(11):1649-1659.

7. O'Brien ME, Wigler N, Inbar M, et al. Reduced cardiotoxicity and comparable efficacy in a phase III trial of pegylated liposomal doxorubicin $\mathrm{HCl}$ (CAELYX/Doxil) versus conventional doxorubicin for first-line treatment of metastatic breast cancer. Ann Oncol. 2004;15(3):440-449.

8. Singh S, Sharma A, Robertson GP. Realizing the clinical potential of cancer nanotechnology by minimizing toxicologic and targeted delivery concerns. Cancer Res. 2012;72(22):5663-5668.

9. Sharma A, Madhunapantula SV, Robertson GP. Toxicological considerations when creating nanoparticle-based drugs and drug delivery systems. Expert Opin Drug Metab Toxicol. 2012;8(1):47-69.

10. Cheng Z, Al Zaki A, Hui JZ, Muzykantov VR, Tsourkas A. Multifunctional nanoparticles: cost versus benefit of adding targeting and imaging capabilities. Science. 2012;338(6109):903-910.

11. Albanese A, Tang PS, Chan WC. The effect of nanoparticle size, shape, and surface chemistry on biological systems. Annu Rev Biomed Eng. 2012;14:1-16.

12. Alberts DS, Garcia DJ. Safety aspects of pegylated liposomal doxorubicin in patients with cancer. Drugs. 1997;54 Suppl 4:30-35. 
13. Immordino ML, Dosio F, Cattel L. Stealth liposomes: review of the basic science, rationale, and clinical applications, existing and potential. Int J Nanomedicine. 2006;1(3):297-315.

14. Muggia FM, Hainsworth JD, Jeffers S, et al. Phase II study of liposomal doxorubicin in refractory ovarian cancer: antitumor activity and toxicity modification by liposomal encapsulation. J Clin Oncol. 1997;15(3):987-993.

15. Muggia FM. Clinical efficacy and prospects for use of pegylated liposomal doxorubicin in the treatment of ovarian and breast cancers. Drugs. 1997;54 Suppl 4:22-29.

16. Lv H, Zhang S, Wang B, Cui S, Yan J. Toxicity of cationic lipids and cationic polymers in gene delivery. J Control Release. 2006;114(1): $100-109$.

17. Akhtar S, Benter I. Toxicogenomics of non-viral drug delivery systems for RNAi: potential impact on siRNA-mediated gene silencing activity and specificity. Adv Drug Deliv Rev. 2007;59(2-3):164-182.

18. Dokka S, Toledo D, Shi X, Castranova V, Rojanasakul Y. Oxygen radical-mediated pulmonary toxicity induced by some cationic liposomes. Pharm Res. 2000;17(5):521-525.

19. Lam W, Leung CH, Chan HL, Fong WF. Toxicity and DNA binding of dextran-doxorubicin conjugates in multidrug-resistant KB-V1 cells: optimization of dextran size. Anticancer Drugs. 2000;11(5):377-384.

20. Brooks D, Okeefe P, Buncke HJ. Dextran-induced acute renal failure after microvascular muscle transplantation. Plast Reconstr Surg. 2001;108(7):2057-2060.

21. Chang $\mathrm{C}$. The immune effects of naturally occurring and synthetic nanoparticles. J Autoimmun. 2010;34(3):J234-J246.

22. Rutberg FG, Dubina MV, Kolikov VA, et al. Effect of silver oxide nanoparticles on tumor growth in vivo. Dokl Biochem Biophys. 2008;421: 191-193.

23. Hussain SM, Hess KL, Gearhart JM, Geiss KT, Schlager JJ. In vitro toxicity of nanoparticles in BRL 3A rat liver cells. Toxicol In Vitro. 2005;19(7):975-983.

24. Garg T, Singh O, Arora S, Murthy R. Scaffold: a novel carrier for cell and drug delivery. Crit Rev Ther Drug Carrier Syst. 2012;29(1):1-63.

25. Ladewig K. Drug delivery in soft tissue engineering. Expert Opin Drug Deliv. 2011;8(9):1175-1188.

26. Szentivanyi A, Chakradeo T, Zernetsch H, Glasmacher B. Electrospun cellular microenvironments: understanding controlled release and scaffold structure. Adv Drug Deliv Rev. 2011;63(4-5):209-220.

27. Mawad D, Boughton EA, Boughton P, Lauto A. Advances in hydrogels applied to degenerative diseases. Current Pharm Des. 2012;18(18): 2558-2575.

28. Kurobe H, Maxfield MW, Breuer CK, Shinoka T. Concise review: tissue-engineered vascular grafts for cardiac surgery: past, present, and future. Stem Cells Transl Med. 2012;1(7):566-571.

29. Ferreira AM, Gentile P, Chiono V, Ciardelli G. Collagen for bone tissue regeneration. Acta Biomater. 2012;8(9):3191-3200.

30. Meinel AJ, Germershaus O, Luhmann T, Merkle HP, Meinel L. Electrospun matrices for localized drug delivery: current technologies and selected biomedical applications. Eur J Pharm Biopharm. 2012;81(1):1-13.

31. Sill TJ, von Recum HA. Electrospinning: applications in drug delivery and tissue engineering. Biomaterials. 2008;29(13):1989-2006.
32. He Q, Wang X, Zhang X, et al. A tissue-engineered subcutaneous pancreatic cancer model for antitumor drug evaluation. Int J Nanomedicine. 2013;8:1167-1176.

33. Wang X, Zhang X, Fu Z, Yin H. A bioengineered metastatic pancreatic tumor model for mechanistic investigation of chemotherapeutic drugs. J Biotechnol. 2013; 166(4):166-173

34. Conroy T, Desseigne F, Ychou M, et al. FOLFIRINOX versus gemcitabine for metastatic pancreatic cancer. $N$ Engl J Med. 2011;364(19): 1817-1825.

35. Thomas V, Zhang X, Catledge SA, Vohra YK. Functionally graded electrospun scaffolds with tunable mechanical properties for vascular tissue regeneration. Biomed Mater. 2007;2(4):224-232.

36. Zhang X, Thomas V, Vohra YK. In vitro biodegradation of designed tubular scaffolds of electrospun protein/polyglyconate blend fibers. J Biomed Mater Res B Appl Biomater. 2009;89(1):135-147.

37. Lin CW, Tseng SJ, Kempson IM, Yang SC, Hong TM, Yang PC. Extracellular delivery of modified oligonucleotide and superparamagnetic iron oxide nanoparticles from a degradable hydrogel triggered by tumor acidosis. Biomaterials. 2013;34(17):4387-4393.

38. Zeng YF, Tseng SJ, Kempson IM, Peng SF, Wu WT, Liu JR. Controlled delivery of recombinant adeno-associated virus serotype 2 using pH-sensitive poly(ethylene glycol)-poly-L-histidine hydrogels. Biomaterials. 2012;33(36):9239-9245.

39. Blaszkowsky L. Treatment of advanced and metastatic pancreatic cancer. Front Biosci. 1998;3:E214-E225.

40. Teo WE, He W, Ramakrishna S. Electrospun scaffold tailored for tissuespecific extracellular matrix. Biotechnol J. 2006;1(9):918-929.

41. Zhang X, Xu Y, Thomas V, Bellis SL, Vohra YK. Engineering an antiplatelet adhesion layer on an electrospun scaffold using porcine endothelial progenitor cells. J Biomed Mater Res A. 2011;97(2):145-151.

42. Zhang X, Thomas V, Xu Y, Bellis SL, Vohra YK. An in vitro regenerated functional human endothelium on a nanofibrous electrospun scaffold. Biomaterials. 2010;31(15):4376-4381.

43. Zhang X, Thomas V, Vohra YK. Two ply tubular scaffolds comprised of proteins/poliglecaprone/polycaprolactone fibers. J Mater Sci Mater Med. 2010;21(2):541-549.

44. Thomas V, Zhang X, Vohra YK. A biomimetic tubular scaffold with spatially designed nanofibers of protein/PDS bio-blends. Biotechnol Bioeng. 2009;104(5):1025-1033.

45. Liao IC, Chen S, Liu JB, Leong KW. Sustained viral gene delivery through core-shell fibers. J Control Release. 2009;139(1):48-55.

46. Reya T, Morrison SJ, Clarke MF, Weissman IL. Stem cells, cancer, and cancer stem cells. Nature. 2001;414(6859):105-111.

47. Kure S, Matsuda Y, Hagio M, Ueda J, Naito Z, Ishiwata T. Expression of cancer stem cell markers in pancreatic intraepithelial neoplasias and pancreatic ductal adenocarcinomas. Int J Oncol. 2012;41(4):1314-1324.

48. Hermann PC, Huber SL, Herrler T, et al. Distinct populations of cancer stem cells determine tumor growth and metastatic activity in human pancreatic cancer. Cell Stem Cell. 2007;1(3):313-323.

49. Maeda S, Shinchi H, Kurahara H, et al. CD133 expression is correlated with lymph node metastasis and vascular endothelial growth factor-C expression in pancreatic cancer. Br J Cancer. 2008;98(8): 1389-1397.
International Journal of Nanomedicine

\section{Publish your work in this journal}

The International Journal of Nanomedicine is an international, peerreviewed journal focusing on the application of nanotechnology in diagnostics, therapeutics, and drug delivery systems throughout the biomedical field. This journal is indexed on PubMed Central, MedLine, CAS, SciSearch ${ }^{\circledR}$, Current Contents ${ }^{\circledR} /$ Clinical Medicine,

\section{Dovepress}

Journal Citation Reports/Science Edition, EMBase, Scopus and the Elsevier Bibliographic databases. The manuscript management system is completely online and includes a very quick and fair peer-review system, which is all easy to use. Visit http://www.dovepress.com/ testimonials.php to read real quotes from published authors. 